\title{
A organização social como verdadeiro objeto da crítica no Segundo Discurso ${ }^{1}$
}

\section{Social organization as the true object of criticism in the Second Discourse}

\subsection{0/1983-2109.2021v28n55ID21424}

Julio Tomé

Universidade Federal de Santa Catarina (UFSC)

D 0000-0002-2840-2410

juliohc7@hotmail.com

Resumo: A ideia de que as desigualdades naturais não implicam em desigualdades políticas e morais (i.e., desigualdades sociais) deve ser vista como o ponto de partida do diagnóstico apresentado por Rousseau no Segundo Discurso. As desigualdades sociais tornam-se parte da vida humana somente após a passagem do estado de natureza para o estado civil. O estado civil seria um estado artificial e de desordem, no qual as pessoas desenvolvem a faculdade do aperfeiçoamento (ou perfectibilidade) e, consequentemente, o sentimento (artificial) do amor-próprio. Com o desenvolvimento do amor-próprio, as pessoas começam a se comparar umas com as outras e desejam ser mais estimadas que as demais por seus semelhantes. Desse modo, o amor-próprio seria o grande responsável pelo desenvolvimento das desigualdades sociais entre as pessoas. Esse trabalho, porém, deseja mostrar que o amor-próprio, enquanto um sentimento artificial, é, em si mesmo, ambíguo e dependente das condições sociais que está inserido. Dessa forma, o amor-próprio pode ser inflamado ou igualitarista, dependendo do modo pelo qual as instituições sociais estarão organizadas. E as desigualdades sociais não podem ser vistas como uma

${ }^{1}$ O presente trabalho foi realizado com apoio da Coordenação de Aperfeiçoamento de Pessoal de Nível Superior - Brasil (CAPES) - código de Financiamento 001. 
implicação direta do amor-próprio, pois dependeriam dos arranjos sociais. A partir dessa leitura de Rousseau, haveria uma teoria normativa das desigualdades sociais, que seriam independentes das ações humanas, na qual a ideia de que as pessoas são naturalmente boas permanece assegurada e se pode defender a continuidade entre as obras do filósofo genebrino, bem como a possibilidade da criação de um estado civil justo (frente ao diagnóstico do Segundo Discurso).

Palavras-chave: Amor-Próprio; Consentimento; Desigualdades Sociais; Rousseau.

Abstract: The idea that natural inequalities do not imply political and moral inequalities (i.e., social inequalities) should be seen as the starting point of the diagnosis presented by Rousseau in the Second Discourse. Social inequalities become part of human life only after the transition from the state of nature to the civil state. The civil state would be an artificial and disorderly state, in which people develop the faculties of improvement (or perfectibility) and, consequently, the (artificial) feeling of amour-propre (self-love). With the development of amour-propre, people begin to compare themselves with each other and wish to be more esteemed than others by their fellow human. In this way, amour-propre would be largely responsible for the development of social inequalities between people. This work, however, wishes to show that amour-propre, as an artificial feeling, is, in itself, double and dependent on the social conditions that it is inserted. Thus, amour-propre can be inflamed or egalitarian depending on the way in which social institutions are organized. And social inequalities cannot be seen as a direct implication of amour-propre, since they would depend on social arrangements. From this reading of Rousseau, there is a normative theory of social inequalities, which is independent of human actions in which the idea that people are naturally good remains assured and one can defend the idea of continuity between the works of the Genevan philosopher as well as the possibility of the creation of a just civil state (in face of the diagnosis presented in the Second Discourse).

Keywords: Amour-propre. Consent. Social Inequalities. Rousseau. 


\section{As desigualdades no Segundo Discurso: do amor-próprio aos arranjos sociais como verdadeiros objetos da crítica}

Rousseau, no seu célebre Discurso Sobre a Origem e os Fundamentos da Desigualdade entre os Homens (também conhecido como Discurso sobre a Desigualdade, ou ainda Segundo Discurso, de 1754), afirma que a questão da desigualdade é uma das mais interessantes que a filosofia pode propor e ao mesmo tempo uma das mais espinhosas que os filósofos e as filósofas podem resolver. O filósofo genebrino afirma que existem dois tipos de desigualdades, que são independentes entre si, a saber, a desigualdade natural ou física e a desigualdade política ou moral. A desigualdade natural ou física diferencia as espécies entre si, assim como os membros de cada espécie, e é "[...] estabelecida pela natureza e consiste na diferença das idades, da saúde, das forças do corpo e das qualidades do espírito ou da alma [...]" (ROUSSEAU, 2013, p. 21). Já a desigualdade política ou moral (i.e., sociais) ${ }^{2}$ é própria aos seres humanos, mas existe apenas no estado civil, pois é dependente "[...] de uma espécie de convenção e é estabelecida, ou pelo menos autorizada, pelo consentimento dos homens" (ROUSSEAU, 2013, p. 21).

Para investigar as desigualdades entre as pessoas ${ }^{3}$, Rousseau

${ }^{2}$ Esse trabalho aceitará a ideia de Neuhouser (2014), que afirma que o termo desigualdades sociais é mais exato do que desigualdades morais e políticas, pois "moral" não possui hoje o mesmo significado que possuía para Rousseau e "político" é um termo muito estreito para capturar todas as desigualdades examinadas por Rousseau. Desse modo, todas as vezes que o termo desigualdades sociais aparecer, ele estará se referindo as desigualdades morais e políticas expressas no pensamento de Rousseau, designando, como colocado por Neuhouser (2014), que as investigações de Rousseau são sobre desigualdades que possuem uma origem social e são da natureza social, conforme dão vantagens relativas ou privilégios para algumas pessoas em detrimento de outras.

${ }^{3}$ Tentou-se neste trabalho, ao máximo, dentro das possibilidades ofertadas pela língua portuguesa, adaptar a linguagem rousseauniana para uma linguagem neutra e que não privilegiasse um gênero (os homens) frente ao outro (as mulheres), uma vez que se acredita que a democracia só é possível com real igualdade entre as 
(2013 [1754]) julga necessário que se faça um regresso à primeira distinção entre elas, pois as pessoas nascem iguais entre si e só começam a se diferenciar a partir do momento que diversas causas físicas introduzem, em algumas espécies, as variedades que se conhece. Desse modo, há uma desigualdade natural entre as várias espécies de animais, mas também uma desigualdade natural entre os indivíduos de uma mesma espécie e, portanto, entre cada pessoa. Mas existir desigualdades naturais não implica, no pensamento do filósofo genebrino, na legitimação das desigualdades de renda e riqueza. As desigualdades naturais ou físicas, portanto, não são um problema para Rousseau. O problema seria as desigualdades sociais, que não são implicações das desigualdades naturais entre as pessoas, mas desigualdades morais ou políticas, advindas da convenção social aceita pelas pessoas e, portanto, artificiais. Desse modo, as desigualdades artificiais só são possíveis em um estado também artificial, i.e., no estado civil - que é visto por Rousseau como um estado de corrupção e desordem -, pois é a partir da instituição do Estado Civil que as pessoas começam a se comparar

pessoas, independentemente dos gêneros ou de quaisquer outras diferenças que as pessoas possam possuir. Além disso, com Cohen (2010), julgou-se que apesar das considerações um tanto quanto problemáticas de Rousseau sobre as mulheres em suas obras, não há nenhum problema, ao menos de forma mais abstrata, de se colocar as mulheres também como pessoas políticas, inclusive na lógica do pensamento de Rousseau. Portanto, como colocado por Cohen (2010), a ideia de Rousseau sobre o fato de que as mulheres deveriam ser excluídas da política - ideia justificada pelo filósofo genebrino por meio da "natureza" das mulheres - pode ser contornada pela própria filosofia política de Rousseau, i.e., que é possível reconstruir a filosofia política de Rousseau abstraindo de sua opinião que as diferenças sexuais naturais têm um significado social decisivo. Desse modo, sempre que Rousseau utilizou o termo "homens" alterou-se para "pessoas", "sujeitos", "seres-humanos" ou termos semelhantes. Sabe-se que com isso não se resolve o problema da misoginia e do machismo no pensamento de Rousseau, mas se julgou que a teoria política de Rousseau, apesar de ter sido colocada sob a forma de um sujeito masculino, branco e europeu, diz respeito a todas as pessoas de uma comunidade política, seja homem, mulher, cis ou trans, branco ou negro, europeu ou um sujeito do atlântico sul, uma vez que a democracia, ao menos assim se acredita neste trabalho, possui um valor universal e absoluto, mas que só é possibilitada quando todas as pessoas, de igual modo, podem se sentir participantes cooperativas com o status de igualdade reconhecido. 
umas com as outras.

No pensamento de Rousseau (2013), a partir da instituição do estado civil abre-se caminho para o desenvolvimento do amorpróprio $^{4}$, que é um sentimento artificial, decorrente da faculdade humana responsável pelo desenvolvimento de todas as outras faculdades humanas, a saber, a faculdade do aperfeiçoamento (ou perfectibilidade). O amor-próprio é um sentimento artificial, relativo, nascido na sociedade e que faz os seres humanos considerarem a si próprios como mais importantes que as demais pessoas. Dessa forma, as pessoas querem ser reconhecidas como as melhores, as mais estimadas, as mais bonitas etc. Segundo Rousseau (2013), o amor-próprio é diferente do amor de si mesmo, pois enquanto o último é um sentimento natural que está presente já no estado de natureza, assim como a compaixão ou a pena, e é visto como um sentimento natural que leva todo animal a zelar pela própria conservação - e nos seres humanos produz a humanidade e a virtude - o amor-próprio é um sentimento artificial, presente apenas no Estado Civil, e é a origem da honra entre as pessoas, assim como a fonte de todos os males que uma pessoa realiza aos demais membros de sua espécie. É a partir do amor-próprio que as pessoas começam a se comparar umas com as outras e as desigualdades passam a ter importância. As desigualdades sociais, portanto, possuem uma relação direta com o amor-próprio, pois é esse sentimento artificial que permite que as desigualdades morais e políticas se firmem e sejam percebidas entre as pessoas.

De acordo com Maurizio Viroli (2003), as pessoas (selvagens) no Estado de Natureza não se comparam umas às outras, pois não possuem o sentimento da autoestima, de modo que uma pessoa até

\footnotetext{
${ }^{4}$ Como será visto mais ao fim desse artigo, Rousseau designa estado civil como uma configuração política que é posterior ao contrato social, no qual cria-se uma autoridade soberana e as leis positivas comuns a todas as pessoas da sociedade, porém a passagem do estado de natureza para o estado civil não se dá de forma direta e retilínea (como era nos outros contratualistas clássicos). Mais sobre isso na seção II desse artigo. Coutinho (1996) explica de forma magistral esse processo de formação do estado civil em Rousseau.
} 
pode perceber que está sendo prejudicada pela ação de outra pessoa, mas não possuirá a ideia de que está sendo injustiçada, pois é incapaz de experimentar o ressentimento, a vaidade, a consideração pelas demais pessoas, assim como a própria estima ou o desprezo.

A imaginação, que causa tanta devastação entre nós, não fala a corações selvagens; cada um espera tranquilamente o impulso da natureza, entrega-se a ele sem escolha, com mais prazer do que furor, e, satisfeita a necessidade, todo o desejo se extingue.

Portanto, é incontestável que o amor, assim como todas as outras paixões, só adquiriu na sociedade esse ardor impetuoso que o torna tão frequentemente funesto aos homens, e é ridículo representar os selvagens como incessantemente matando-se entre si para saciar sua brutalidade, opinião diretamente contrária à experiência, pois os caraíbas, que de todos os povos existentes é o que menos se afastou do estado de natureza, são precisamente os mais pacíficos em seus amores e os menos sujeitos ao ciúme, embora vivendo sob um clima quente que parece dar a essas paixões uma maior atividade (ROUSSEAU, 2013, p. 34).

Segundo Viroli (2003), no pensamento de Rousseau, quando as pessoas abandonam o mundo puramente natural, a comparação que antes não existia - passa a ser a norma, e nasce a ideia de indivíduo. A partir da comparação mútua (quando as pessoas começam a se preocupar sobre quem dança melhor, é mais bonito, tem a melhor casa etc.) é que a identidade individual nasce. Assim, as pessoas, que antes se viam como pertencendo a uma coletividade, começam a se entender como indivíduos, que são diferentes entre si, distintos uns dos outros. Segundo Viroli (2003) o preço a ser pago pela identidade individual - onde as pessoas se veem como um ser diferente das outras pessoas de sua espécie - é a desordem, que "[...] significa um complexo de relações entre indivíduos em que cada um está em conflito com os outros e cada um procura melhorar o seu destino à custa dos seus semelhantes. A desordem ocorre quando cada indivíduo acredita ser o centro em torno do qual tudo o mais deve gira [...]" (VIROLI, 2003, p. 30-31)

Destaca-se que, para Viroli (2003), a teoria da desigualdade de Rousseau deve ser vista possuindo uma ligação com a ideia de 
ordem hierárquica, a qual consiste em tudo estar no seu "lugar certo". O autor define ordem como a alocação de cada parte do todo em uma posição e lugar apropriado, i.e., ordem implica uma série de posições e lugares, sobre as quais algumas são mais elevadas do que outras, com a ideia de que não é apenas cada parte que deve desempenhar um papel, mas que também existem diferentes graus de mérito e de valor. E, uma vez que a desordem é um subproduto do ódio e inimizade gerados quando as pessoas se envolvem na luta pela preeminência, o prêmio que elas disputam não é um bem absoluto, mas relacional e, portanto, a riqueza, a estima, o respeito e a posição social são valorizados enquanto um objeto de status, em que é preferível tê-lo a não possuí-lo, é preferível ter uma quantidade maior do que menor, pois assim se alcançará um status maior, em comparação com as demais pessoas. A ideia é que os conceitos de ordem/desordem abraçam duas concepções subordinadas: a alocação de indivíduos para um nível específico na hierarquia de status e a noção de conflito.

A tese de Viroli (2003) é, portanto, que se deve ler o conceito de desigualdade elaborado por Rousseau pela lupa da ordem (e da desordem), pois se conseguiria revelar as várias dimensões do conceito de desigualdade presentes no pensamento de Rousseau, nas quais as divergências entre as pessoas devem ser explicadas por meio do anseio de distinção presente nos seres humanos, e não na busca por meios materiais e riqueza, uma vez que o objeto da competição humana seria o status - e não os bens econômicos ${ }^{5}$. Pode-se, de forma bastante resumida, afirmar que na visão de Viroli (2003), portanto, a individuação é a responsável pelas desigualdades no pensamento de Rousseau, pois é a partir do momento que as pessoas começam a se perceber como "um", como indivíduo singular, que surge o egoísmo. E é por causa do egoísmo

\footnotetext{
${ }^{5}$ Viroli (2003) afirma que até mesmo a instituição da propriedade privada pode ser vista pela ideia de competição pelo respeito, só que, a partir do desenvolvimento da instituição dos direitos de propriedade, as desigualdades entre as pessoas passaram a ter um componente social real (posteriormente se voltará a tratar da questão da propriedade humana).
} 
que as pessoas se colocam em uma situação de comparação, almejando serem mais estimadas que as demais, i.e., que permitem que o amor-próprio assuma o seu lugar na sociedade.

Neuhouser (2008), por sua vez, afirma que o que faz o amorpróprio ser a fonte (source) ou causa (cause) das desigualdades sociais no pensamento de Rousseau é o fato de este sentimento (artificial) implicar em fins relativos (i.e., o desejo de uma pessoa ser reconhecida por outra como possuidora de um determinado bem, pois, assim, sua busca não é em vista do seu próprio bem-estar, mas visando que as outras pessoas a reconheçam como digna de estima). Neuhouser (2008), portanto, concorda com a colocação de Viroli (2003) - que o problema das desigualdades em Rousseau é relacional -, porém, afirma que há uma diferenciação entre estima e respeito, sobre a qual, enquanto o respeito é algo atribuído à todas as pessoas e que todas são merecedoras, independentemente de seus status, classes ou quaisquer outras diferenças que as pessoas possam fazer entre si, a estima é vista como a capacidade de uma pessoa considerar outra pessoa como merecedora de elogio, admiração ou emulação devido a alguma qualidade ou realização em específico. A estima é a valorização de uma pessoa, não é algo que todas as pessoas têm direito ou são merecedoras e agraciadas. A estima é direcionada para algumas pessoas em específico, por ações, qualidades ou feitos específicos. Por exemplo: estima-se o Maradona por tudo o que ele fez ao futebol. E isso é diferente do respeito, que deve ser distribuído de igual modo a todas as pessoas (assim, mesmo que o Maradona não tivesse sido o jogador que foi, ele mereceria respeito).

Neste ponto, cabe salientar que Dent (1989) afirma que haveria duas leituras possíveis do amor-próprio. Cada uma dessas leituras seria o reflexo da maneira pela qual uma pessoa se autovalorizaria (i.e., a forma pela qual a estima seria desejada). A primeira forma é chamada de amor-próprio igualitarista, enquanto a segunda recebe a denominação de amor-próprio inflamado. Dent (1989) afirma que o amor-próprio inflamado (excessivo) tem como sua principal característica o ato da pessoa se colocar no centro das considerações 
das outras pessoas, i.e., o amor-próprio inflamado faz com que as pessoas desejem possuir as melhores estimas. Desse modo, uma pessoa vê as outras como concorrentes, como hostis, enganosas e desonestas. O amor-próprio inflamado cria um significado para os outros que nega diretamente a possibilidade de alcance de seu próprio objetivo inerente, o de assegurar uma posição categoricamente reconhecida. E isso é diferente do amor-próprio igualitarista, pois, nessa acepção, não se trata de ser preferido diante das demais pessoas, ter uma palavra maior e mais "influência", como condição para que se sinta estabelecido como "pessoa". Dent (1989) afirma que o amor-próprio igualitarista pode atingir seu próprio objetivo se, e somente se, ele (o amor-próprio) permitir e conceder aos outros dignidade e peso igual.

Cohen (2010) aceita a diferenciação feita por Dent, e afirma que o amor-próprio igualitarista faz com que uma pessoa veja seu valor como igual ao das outras pessoas, sendo essa uma forma de autoestima que é razoável, tanto de maneira intrínseca, quanto instrumental. O amor-próprio inflamado, para Cohen (2010), é uma forma não igualitária de se ver o amor-próprio, pois a partir dele uma pessoa se vê como mais digna de consideração que as demais pessoas; ela se coloca dando mais importância a si mesma (e aos seus interesses) do que a qualquer outra pessoa, atribuindo o primeiro e melhor lugar para $\mathrm{si}^{6}$. Um traço importante decorrente do pensamento de Cohen (2010) é que vícios, como o ciúme, a indiferença egoísta, a ganância, a crueldade, a inveja e a covardia ${ }^{7}$, são todos alimentados pelo amor-próprio inflamado e, portanto, eles não são originais da natureza humana, nem têm raízes no egoísmo ou em um desejo insaciável de acumular bens - diferentemente da

\footnotetext{
${ }^{6}$ Salienta-se que segundo Cohen (2010), poderia ainda haver uma terceira forma de amor-próprio, uma em que a pessoa se colocasse como inferior às demais pessoas. Porém, Rousseau não considerou essa possibilidade, e, desse modo, o autor não se dedicou à análise dessa perspectiva do conceito. Não se analisará essa possibilidade nesse trabalho.

${ }^{7}$ Por outro lado, pode-se pegar como exemplo do amor-próprio igualitarista o amor pela pátria, visto por Rousseau como um possível destino do amor-próprio em sociedades bem ordenadas. Para mais, confira: Lepan (2007).
} 
tese defendida por Viroli (2003), em que as desigualdades seriam decorrentes do egoísmo humano. De acordo com Cohen (2010), esses vícios refletem uma concepção do valor relativo de uma pessoa, que geram um desejo de viver uma vida melhor do que outras. Assim, Rousseau teria objetivado apresentar uma teoria dos vícios sem ligá-los à natureza humana e, portanto, os vícios humanos seriam produtos dos arranjos sociais em que as pessoas estariam inseridas. Apesar de a autoestima ser intrínseca à natureza humana, sua expressão (igualitária ou não igualitária) dependeria das circunstâncias sociais em que as pessoas estariam inseridas.

Destaca-se que para Neuhouser (2014) - que também está de acordo com a diferenciação entre os tipos de amor-próprio elaborada por Dent (1989) - Rousseau não seria vítima da ilusão de que o respeito sozinho poderia saciar as necessidades humanas de contar como algo aos olhos de seus semelhantes, i.e., mesmo Rousseau retratando a demanda por igual respeito como o desenvolvimento do desejo mais primitivo de uma pessoa, o desejo de ser admirada por suas qualidades particulares não sugere que o respeito possa substituir completamente a estima. Rousseau vê o amor-próprio como um sentimento artificial, pois o amor-próprio move os humanos apenas quando colocados em situações de comparações e julgamentos. Além disso, é um sentimento artificial, pois suas formas são variáveis e dependem do tipo de mundo social que seus possuidores habitam. Dessa maneira, o amor-próprio possui uma dupla característica, não sendo uma força para o bem, mas também não sendo apenas, ou necessariamente, ruim em suas consequências. $\mathrm{O}$ amor-próprio deve ser visto como a principal fonte de muitos males descritos por Rousseau. Contudo, ele não é necessariamente o responsável por conduzir a humanidade a todos esses males. É possível que o amor-próprio assuma formas positivas que são capazes de remediar os próprios males que o desejo inflamado por reconhecimento produz, pois o amor-próprio além de ser uma característica artificial das pessoas, é também dependente de como as organizações sociais são moldadas para determinar seu contexto. 
Com o reconhecimento do amor-próprio igualitarista, Dalbosco (2014) afirma que o amor-próprio - como sentimento eminentemente social - expressa sua característica inflamada quando uma pessoa busca incessantemente pela estima pública, acompanhada pelo desejo de querer ser, a qualquer custo, superior aos seus semelhantes. Por outro lado, quando o amor-próprio assume sua perspectiva igualitarista, expressa uma visão construtiva, baseada no reconhecimento recíproco. De acordo com Dalbosco (2014), sob a perspectiva do amor-próprio igualitarista há uma ruptura com o ponto de vista individualista-egocêntrico de Rousseau, pois se exige que o ser humano inclua (e avalie) em sua própria ação as consequências que ela trará as demais pessoas de sua sociedade. Segundo o autor, o amor-próprio é concebido como um dos principais sentimentos humanos, que pode inclinar-se tanto aos vícios quanto à virtude, possuindo assim uma dupla direção (inclinação) que constitui o núcleo da própria teoria da ambiguidade do amor-próprio.

Dalbosco (2014) coloca que, por ser um sentimento, o amorpróprio, porém, não pode agir por si mesmo, ele é impulsionado por outra coisa. Esse impulso pode ser a vontade, que quando dirigida construtivamente, pode se tornar virtude. Para Dalbosco (2014) a virtude nada mais é do que o impulso ético da vontade, fazendo com que o amor-próprio canalize as suas forças (paixões) na direção construtiva. Desse modo, quando uma pessoa é movida pelo amor à justiça, o amor-próprio torna-se cooperativo e solidário, deixando de ser vaidoso, petulante ou egoísta. Dalbosco (2014) afirma que a vontade virtuosa é aquela capaz de assegurar a igualdade nas relações humanas e sociais. O autor julga que "o vínculo da teoria do amor-próprio com a formação virtuosa da vontade é o núcleo do pensamento filosófico e pedagógico de Rousseau, porque serve tanto para 'corrigir' a tendência pessimista de seus escritos de crítica à cultura quanto para oferecer a base formativo-educacional necessária aos ideais normativos que sustentam a concepção antropológica, política e jurídica do genebrino" (DALBOSCO, 2014, 
p. 810$)^{8}$.

Uma vez que as pessoas buscam satisfazer o amor-próprio, elas dependem dos tipos de oportunidades de reconhecimento que as sociedades em que estão inseridas incentivam ou permitem. Os vários esquemas (possíveis) de desigualdade, dentro de cada sociedade, desempenham papéis fundamentais nas definições das oportunidades que as pessoas terão disponíveis às suas mãos e, consequentemente, nos tipos de desigualdades permissíveis. De acordo com Neuhouser (2014), em uma sociedade que as disparidades de riqueza são limitadas e há o encorajamento para que as pessoas encontrem o sentido de suas próprias existências, são geradas determinadas aspirações de reconhecimento em seus membros. Essas aspirações de reconhecimento serão diferentes quando comparadas, por exemplo, a uma sociedade que possui ordem social baseada em privilégios herdados de classe. Segundo essa leitura, as instituições sociais têm, em outras palavras, efeitos educativos ou formativos sobre seus membros, e isso explica por que se pode dizer que as desigualdades sociais de todos os tipos desempenham um papel importante na produção dos males gerados pelo amor-próprio inflamado.

Dessa forma, segundo Neuhouser (2014), a avaliação normativa e a crítica de Rousseau são dirigidas apenas aos estados de coisas em relação aos quais as pessoas concernidas têm responsabilidade. Cabe destacar que no pensamento de Rousseau o mundo social é artificial e, portanto, as práticas e instituições que caracterizam qualquer sociedade em particular são produtos das ações coletivas dos seres humanos, e são sustentadas apenas pela participação contínua e o consentimento de seus membros. Os processos de socialização dão formas particulares aos desejos e ideais que motivam os indivíduos, e assim as instituições sociais reais inevitavelmente encorajam certos modos de se encontrar determinados tipos de reconhecimento, enquanto excluem outros.

8 Mais à frente se defenderá essa continuidade entre os trabalhos de Rousseau apontada por Dalbosco (2014). 
Há casos, porém, em que as desigualdades naturais podem se entrelaçar com as desigualdades sociais e, conforme Neuhouser (2014), uma vez que as práticas e instituições sociais desempenham um grande papel na determinação das consequências que as desigualdades naturais têm nas vidas dos desfavorecidos, elas podem ser vistas como resultados das próprias ações sociais, e são, portanto, assunto apropriado para a questão normativa do Segundo Discurso. O autor cita, para exemplificar seu ponto, que as chances - ou falta delas - que uma pessoa que nasce cega e que outra sem qualquer deficiência terão ao longo de suas vidas dependerão do modo como as instituições lidarão com as deficiências, i.e., se a cegueira natural não é em si uma injustiça (já que as desigualdades naturais não são justas ou injustas), o fato de que, na maioria das sociedades contemporâneas, as pessoas cegas possuem pouco acesso às instituições educacionais ou ao transporte público, enquanto as pessoas não cegas conseguem acessá-las sem maiores problemas, deve ser visto como uma injustiça e um legítimo objeto de crítica, pois estes fatos são consequências sociais, diferentemente da cegueira, que não é do alcance social mudar.

Segundo Neuhouser (2014), esse ponto exemplificaria bem o pensamento de Rousseau, pois as desigualdades naturais fazem pouca diferença quando comparadas com os efeitos das desigualdades sociais e artificiais. Dessa maneira, quando se observa as desigualdades das sociedades modernas, percebe-se que a origem está muito mais associada com os resultados das circunstâncias sociais do que com circunstâncias naturais. Evidencia-se, assim, o caráter arbitrário das desigualdades. Em sociedades nas quais, por exemplo, o sistema educacional não está adequado para receber estudantes com algum tipo de deficiência visual, como a cegueira, as desigualdades resultantes não podem ser explicadas por meio das desigualdades naturais, mas há um caráter social (como o fato de não haver computadores com softwares para pessoas deficientes, livros em Braille etc.), ainda que implícito, que exclui as pessoas cegas das mesmas chances e oportunidades educacionais. Assim:

[...] O capitalismo, por exemplo, oferece a seus participantes diferentes 
formas de reconhecimento social daquelas que estavam disponíveis sob o feudalismo medieval ou o socialismo do bloco oriental; da mesma forma, os estados que salvaguardam os direitos individuais concedem a seus membros um tipo de reconhecimento que não pode ser obtido em um regime despótico [...] (NEUHOUSER, 2008, p. 41).

\section{A dialética de Rousseau: o papel do consentimento nas desigualdades sociais}

Neuhouser (2008) afirma que Rousseau não acredita que tais forças determinem completamente como os seres humanos se definem, pois os seres humanos possuem o livre arbítrio e, portanto, a capacidade de refletir e transformar seus ideais e autoavaliações. Cabe aqui destacar que, de acordo com Neuhouser (2014), o próprio desenvolvimento da perfectibilidade, no pensamento de Rousseau, depende do livre-arbítrio, pois não é algo desejado por aquele que está se desenvolvendo, mas é uma consequência não intencional de ações livremente escolhidas direcionadas para outros fins. Assim, o processo de civilização (e de consequente degradação da espécie) é decorrente das ações humanas - são produtos da ação livre -, mas as pessoas não podem ser vistas como moralmente culpadas.

Cassirer (1999) coloca que nem Deus, nem as pessoas, individualmente, são responsáveis pelos males que acometem as vidas das pessoas. É à sociedade humana, enquanto um sujeito, que é imputada a responsabilidade pelos males da vida coletiva. Com isso, porém, não se quer dizer que Rousseau é um defensor da vida fora da sociedade. Para o pensador genebrino, a sociedade possui um caráter duplo, no qual, se por um lado ela é a responsável por causar as "[...] mais profundas feridas à humanidade [...]", por outro lado, segue o autor, "[...] somente ela é que também pode e deve curar tais feridas [...]" (CASSIRER, 1999, p. 74). Cassirer (1999) afirma que a pessoa natural não pode escapar da sociedade, mas que pode recriá-la, para também recriar-se. Dessa forma, evidencia-se o caráter reformista do pensamento rousseauniano, no qual as pessoas podem reorganizar suas sociedades para serem as menos injustas (ou mais justas) possíveis. O autor afirma que Rousseau é o primeiro a imputar uma responsabilidade à sociedade, 
sendo uma ideia nova que até o século XVII não se possuía, e tornando-se uma semente germinada até hoje.

Destaca-se a perfectibilidade humana, no pensamento de Rousseau, pois ela possui um caráter duplo e antagônico. É a partir da perfectibilidade humana que nasce toda a inteligência humana, assim como brota a virtude humana; mas, também, é graças a ela que os erros humanos surgem. Segundo Cassirer (1999), a perfectibilidade enreda as pessoas e as leva às desigualdades e à servidão. Por outro lado, somente a perfectibilidade pode guiar as pessoas na direção da saída do labirinto em que ela própria colocou as pessoas - a perfectibilidade é a algoz, mas é também a heroína , pois ela é a única capaz de abrir caminho novamente para a liberdade humana, uma vez que a liberdade só existe na medida em que as próprias pessoas podem conquistá-la, e sua posse é inseparável dessa conquista constante. "[...] Por isso, o que Rousseau exige da comunidade humana e o que ele espera de sua estruturação futura não é que ela aumente a felicidade do homem [i.e., das pessoas], o seu bem-estar e os seus prazeres, mas assegurelhe a liberdade devolvendo-o assim à sua verdadeira determinação [...]" (CASSIRER, 1999, p. 101).

Essa dialética (ou o caráter ambíguo) da liberdade e da perfectibilidade é explicada por Coutinho (1996) por meio da afirmação de que apenas o conceito de liberdade deve ser visto como determinação essencial das pessoas, i.e., como um atributo natural, e não resultante de um processo de socialização. A liberdade, assim, é entendida como autonomia (e liberdade positiva), mas não só, pois é algo que se articula ontologicamente (i) com o caráter dinâmico das pessoas e (ii) com a perfectibilidade (ou faculdade do aperfeiçoamento). Assim, segundo Coutinho (1996), a liberdade de Rousseau atualiza-se por meio da práxis social e manifesta-se mais como um processo do que como um estado. "[...] É preciso levar em conta essa dimensão social e dinâmica do conceito de liberdade em Rousseau se se quer compreender plenamente o significado político da liberdade que ele irá colocar como pressuposto e resultado da sociedade gerada pelo contrato social legítimo" (COUTINHO, 1996, 
p. 12, grifos do autor).

Para Neuhouser (2008), o filósofo genebrino, assim como Sartre posteriormente, defende que a liberdade está em ação mesmo quando os humanos simplesmente assumem os papéis e ideais que lhes são dados por seu mundo social. Segundo Neuhouser, é por isso que a desigualdade depende de convenções e é perpetuada pelo consentimento das pessoas envolvidas. Dessa forma, viver por autoconcepções (self-conceptions) socialmente prescritas simplesmente aceitar, por exemplo, que a riqueza denota mérito pessoal, ou que os pobres merecem a sua (falta de) sorte - ainda requer a participação e o consentimento das pessoas envolvidas.

Para Neuhouser (2014), a ideia de Rousseau de que a desigualdade social depende do consentimento humano é algo intrigante, ao ponto de que inicialmente parece ser uma ideia incorreta, ou mesmo perversa, pois coloca sob as costas das pessoas, inclusive das menos favorecidas, o fato de existir desigualdades. Neuhouser (2014), porém, afirma que a maior preocupação de Rousseau no Segundo Discurso não é a verdadeira origem histórica da desigualdade social, mas saber como e por que, uma vez que as desigualdades passaram a existir, elas são mantidas. Desse modo, Neuhouser (2014) afirma que o espanto é desfeito quando se verifica que a desigualdade social ser consentida pelas pessoas, no pensamento rousseauniano, não significa que elas chegaram ao mundo humano por meio do acordo, mas que, uma vez que as desigualdades morais e políticas existem, elas são mantidas por meio de um consentimento, o qual Rousseau chama de autorização. Recorda-se a afirmação de Rousseau no início do Segundo Discurso e que anteriormente foi em parte reproduzida no parágrafo que inicia esse trabalho:

Concebo na espécie humana dois tipos de desigualdade: uma que chamo natural ou física, porque é estabelecida pela natureza e consiste na diferença das idades, da saúde, das forças do corpo e das qualidades do espírito ou da alma; a outra que podemos chamar desigualdade moral ou política, porque depende de uma espécie de convenção e é estabelecida, ou pelo menos autorizada, pelo consentimento dos homens. Esta consiste nos diferentes privilégios que alguns usufruem em detrimento dos outros, 
como o de serem mais ricos, mais honrados, mais poderosos que eles, ou mesmo o de se fazerem obedecer por eles (ROUSSEAU, 2013, p. 21).

Destaca-se que para Rousseau (2013, p. 52) “[...] a desigualdade moral, autorizada apenas pelo direito positivo, é contrária ao direito natural sempre que não coincide, na mesma proporção, com a desigualdade física; distinção que determina suficientemente o que se deve pensar, a esse respeito, sobre a espécie de desigualdade que reina entre todos os povos civilizados [...]". Como consequência desse fato, Neuhouser (2014) afirma que as desigualdades sociais são, para Rousseau, fenômenos essencialmente normativos.

[...] As desigualdades sociais são normativas no sentido de que elas estão inseridas nas práticas humanas, cuja existência depende da crença de seus participantes na bondade, legitimidade ou naturalidade dessas práticas, o que por sua vez implica que nós somos responsáveis pelas desigualdades sociais - elas dependem de nossas próprias ações - de uma forma que não é verdadeira para as desigualdades naturais [...] (NEUHOUSER, 2014, p. 19).

Segundo Neuhouser (2014), portanto, afirmar que as desigualdades sociais são autorizadas pelo consentimento humano não significa que elas sejam legitimadas ou autorizadas (authoritative). Significa, na verdade, que elas são consideradas legítimas por aquelas pessoas que estão sujeitas a elas, e que essa autorização desempenha um papel significativo na manutenção delas. Tal ponto é importante pois evidencia um interessante pensamento de Rousseau, a saber, que as práticas e instituições sociais que sustentam as desigualdades sociais são mantidas, na maior parte, não por meio da força ou pela coerção, mas por um consenso (tácito ou explícito) de que elas são justificadas.

Assim, como afirmado por Neuhouser (2014), se os trabalhadores e as trabalhadoras das empresas capitalistas, do mundo atual, realizam suas oito ou mais horas de jornada de trabalho, dia após dia, sem sabotar a propriedade de seus patrões ou se apropriarem dela, fazem isso não porque temem o poder do Estado, mas porque em algum nível essas pessoas aceitam a legitimidade ou naturalidade dos arranjos sociais que tornam necessários seus trabalhos para suas subsistências, enquanto seus 
patrões têm riquezas suficientes para viverem suas vidas sem precisarem trabalhar, enriquecendo a partir dos frutos dos trabalhos dos seus funcionários e funcionárias. Neuhouser (2014) destaca que o consentimento que autoriza a maioria das desigualdades sociais não é o típico de contratos, mas consiste na manutenção das crenças mais ou menos conscientes sobre a adequação de certas práticas e instituições, que em última instância repousam na liberdade humana (dos próprios concernidos). Dessa maneira, os menos favorecidos são, em certa parte, coniventes com a situação pela qual se encontram, mas eles também podem ser os responsáveis por alterar essa condição.

É importante destacar que, para Rousseau (2013), no momento em que uma pessoa cercou um terreno, e teve a audácia de afirmar aquele pedaço de terra como seu - e houve gente tola o bastante para aceitar e acreditar -, formou-se a sociedade civil. O filósofo genebrino afirma que a instituição da propriedade privada não se deu pela maldade humana, ou pelo desejo de aprisionar e oprimir os outros membros de sua espécie, mas decorreu das condições sociais presentes, i.e., a passagem do Estado de Natureza para o Estado Civil, com o desenvolvimento do aperfeiçoamento humano e do amor-próprio. Destaca-se, como salientado por Neuhouser (2008; 2014), que apesar do amor-próprio ser causa necessária para as desigualdades, ele não é causa suficiente para, por si só, produzilas. Portanto, foi necessário a existência de outros fatores, em especial o ócio (loisir), a divisão do trabalho e a propriedade privada. Desse modo, como elencado por Neuhouser (2008), no Segundo Discurso há uma complementariedade entre o amorpróprio e a instituição da propriedade privada na explicação das desigualdades sociais.

Deve-se salientar que foi a partir do cultivo das terras que surgiu a necessidade de sua divisão, pois foi a partir do reconhecimento da propriedade que foi necessária a instituição das primeiras regras da justiça, uma vez que, para dar a cada um o que é seu, é necessário que cada um possa ter alguma coisa. É importante destacar o fato de que Rousseau, no Discurso sobre a Economia Política (2017 
[1758]), afirmou que o direito à propriedade privada é o mais sagrado de todos os direitos dos cidadãos e cidadãs, mais importante, em alguns aspectos, que a própria liberdade. No pensamento de Rousseau, portanto, a propriedade privada possui um duplo caráter: por um lado, foi a responsável pela instituição do Estado civil e, consequentemente, pelas desigualdades econômicas (de riqueza); por outro lado, é vista enquanto um direito inalienável, que conserva a existência humana e faz com que as pessoas cumpram os pactos acordados.

Segundo J. Cohen (2010), a partir do nascimento da propriedade privada há o aumento de oportunidades para que as pessoas persigam seus desejos de vantagem, com aumento dos benefícios que essa busca poderia proporcionar, mas também com aumento das desigualdades socioeconômicas. Essas desigualdades, segundo o autor, por uma perspectiva não rousseauniana, poderiam ser explicadas, por exemplo, pelo talento das pessoas em cultivarem suas terras (uma defesa do mérito daquele que melhor cultivou sua terra), porém, na visão rousseauniana, enquanto a propriedade permaneceu comum, os talentos tiveram apenas um efeito limitado sobre as desigualdades, pois cada pessoa partilhava, de algum modo, dos frutos dos benefícios criados pelos mais talentosos. Portanto, foi a partir do surgimento da propriedade privada que os frutos criados pelos mais talentosos não foram mais partilhados por todos os membros de uma sociedade, agravando as desigualdades. Dessa maneira, dado o sistema de propriedade privada e especialização, e a crescente desigualdade resultante desse sistema, que se tem um estímulo ao amor-próprio inflamado e os vícios.

Segundo Neuhouser (2008), deve-se ter claro que para Rousseau a solução dos problemas civilizatórios não será por meio da abolição da propriedade privada, a destruição das sociedades, fazendo com que as pessoas voltem a viver nas florestas com os ursos. O projeto de Rousseau deseja encontrar uma solução institucional para os problemas das desigualdades, onde uma das tarefas de tal projeto será descobrir como o mundo social pode ser organizado, de modo a proporcionar aos seus membros maneiras estáveis e menos 
destrutivas de satisfazer suas necessidades fundamentais de consideração para com os outros.

A passagem de um estado de natureza para a sociedade civil não ocorre de forma automática, assim como a ideia de propriedade não surge de uma hora para a outra. Há uma série de processos revolucionários dentro do estado de natureza, pois só se chega ao estado civil quando uma pessoa precisa do auxílio de outra, quando a igualdade desaparece, a propriedade se introduz e o trabalho se torna necessário. Segundo Coutinho (1996), o caminho entre o estado de natureza e o estado civil em Rousseau é mais complexo do que nos outros contratualistas clássicos, de modo que depois do estado de natureza e antes do contrato existe um processo histórico de socialização, no qual o desenvolvimento das forças produtivas gera várias formações sociais, preparando assim as condições de possibilidade para dois diferentes tipos alternativos de contrato: em um há uma perpetuação da sociedade injusta, e no outro gera-se uma sociedade livre e igualitária. Para Coutinho (1996), a historicidade de Rousseau não envolve apenas formações sociais e os regimes políticos, mas também se refere às próprias pessoas, que modificam seus atributos no curso da evolução histórica.

Destaca-se que, para Rousseau, as pessoas não são naturalmente más. Elas são boas por natureza, mas a sociedade e as instituições as corrompem e as tornam más. Para Rousseau (2013) "[...] o homem selvagem e o homem civilizado diferem de tal modo pelo fundo do coração e das inclinações, que o que faz a felicidade suprema de um reduziria o outro ao desespero [...]" (ROUSSEAU, 2013, p. 52). O filósofo genebrino julga que a verdadeira causa disso é o fato de que a pessoa selvagem vive nela mesma, enquanto a pessoa do Estado Civil só sabe viver na opinião das outras pessoas, i.e., é por meio dos julgamentos realizados por terceiros que obtém o sentimento de sua própria existência. Para o filósofo genebrino, as desigualdades sociais são as responsáveis pelos privilégios que algumas pessoas irão usufruir em detrimento de outras, como o fato de haver pessoas mais ricas que outras, mais honradas, poderosas etc., assim como o fato de que algumas pessoas irão conseguir fazer 
com que as outras as obedeçam.

Desse modo, o problema da desigualdade em Rousseau não é tanto a diferença monetária entre as pessoas - a diferença de renda e riqueza -, mas o fato de as desigualdades sociais implicarem em desrespeitos ao status moral de igualdade entre as pessoas. Por isso, a saída do autor, no Contrato Social, não é a abolição da propriedade privada ou a volta (se isso fosse possível) ao estado originário, mas a criação de um estado civil justo, com a instituição de um sistema de propriedade que consiga se mostrar como não prejudicial aos interesses fundamentais das pessoas. A ideia é que quando um sistema social é realizado sob certas condições sociais específicas, ele pode ser legítimo e, portanto, permissível, independentemente de sua relação com quaisquer leis naturais que originalmente regem a aquisição legítima de propriedade. Esse sistema precisaria manter a igualdade social entre as pessoas, pois a questão fundamental do pensamento de Rousseau (2013) é o fato de que as pessoas são vistas como seres morais livres e iguais, que possuem um status igual de cidadania e exercem um poder político igual umas sobre as outras. O problema das desigualdades socioeconômicas (políticas e morais) é justamente minar esse status de igualdade.

Haveria, assim, uma continuidade entre o diagnóstico apresentado por Rousseau no Segundo Discurso e o seu Contrato Social, no qual o filósofo genebrino apresentaria seu prognóstico e sua ideia de sociedade justa. Reconhece-se que essa não é uma leitura aceita por todos os leitores de Rousseau. Por exemplo, Starobinski (1991) afirma que ao se considerar o Contrato Social de modo isolado, tem-se que essa obra se situa no começo da vida social e, dessa forma, a saída do Estado de Natureza não se trata de destruir uma sociedade imperfeita para estabelecer a liberdade igualitária; mas trata-se do estabelecimento da vontade geral e da lei racional, de um só golpe, sem passagens intermediárias ${ }^{9}$.

9 Petroni (2017) afirma que Rousseau teria sido um dos primeiros teóricos modernos que ressaltaram o autogoverno como única condição de justificativa para 
Starobinski (1991) afirma que quando se lê o pensamento de Rousseau em uma totalidade (autorizada pelas lacunas deixadas pelo filósofo genebrino), vê-se uma regularidade maior do que ela realmente é; e esquece-se que há uma pulsação entre a descontinuidade do discurso teórico de Rousseau e a continuidade de um eu subjacente, sobre a qual as próprias rupturas remetem os leitores. Dessa maneira, segundo Starobinski (1991), deve-se, para respeitar a verdade de Jean Jacques, não preencher as lacunas

a imposição de deveres entre pessoas que são vistas como livres e iguais. Para Petroni (2017), no pensamento de Rousseau, se sustentaria a ideia de que "[...] uma norma fornece razões excludentes para ação se, e apenas se, essa norma é fundada no pressuposto de que todas as pessoas estão igualmente autorizadas a demandá-la para todas as demais" (PETRONI, 2017, p. 205). Essa ideia formaria o "ponto de Rousseau", e a partir dele haveria uma relação simétrica de autoridade entre as pessoas. Petroni (2017) salienta que essa ideia é diferente da teoria da soberania apresentada pelo filósofo genebrino n'O Contrato Social. O ponto de Rousseau é apenas um argumento sobre a natureza da autoridade política legítima, que não se propõe a debater a interpretação controversa do conceito de Vontade Geral no pensamento de Rousseau, e nem visa uma forma social específica da efetivação das relações interpessoais. Para o conceito de Vontade Geral em Rousseau, confira: Viroli (2003), Cassirer (1999), Costa (2017), Coutinho (1996), Neuhouser (2008) e Cohen (2010). O tema central de divergência entre as interpretações da Vontade Geral no pensamento de Rousseau é se esse conceito implicaria em uma legitimação de ideias totalitárias ou não - uma vez que a vontade geral não é uma vontade de particulares, nem a soma das vontades, nem a maioria das vontades, mas é geral sobre todos os membros de uma sociedade. Costa (2017, p. 78), por exemplo, afirma que o projeto de Rousseau tem todas as características para transformar "[...] um projeto igualitário num projeto totalitário". Já Coutinho (1996), Neuhouser (2008) e Cohen (2010) colocam-se contrários a interpretações desse tipo. Cohen (2010), por exemplo, defende que pode ser tirada uma defesa da democracia direta a partir da vontade geral de Rousseau. A tese elencada pelo autor é que as pessoas não podem ser sujeitadas às vontades alheias e assim precisam se autogovernar. Petroni (2017), vendo o pensamento de Rousseau de maneira mais contida, afirma que as formas de participação direta e a proibição da representação política (no campo legislativo), pressupostas por Rousseau a partir da ideia de Vontade Geral, podem ser rejeitadas com base no argumento de inclusão deliberativa entre iguais. Segundo Petroni (2017), em um ambiente social complexo, onde se reconhece a existência de um pluralismo de valores e os interesses individuais humanos, não é um problema mostrar que as pressuposições de Rousseau podem estar claramente erradas do ponto de vista do respeito deliberativo. 
deixadas em seu sistema. Starobinski (1991) afirma que as leituras que defendem a continuidade entre as obras de Rousseau podem ser de dois tipos, a saber, Hegeliano/Marxista ou Idealista (Kant/Cassirer), e por meio delas haveria uma encruzilhada, onde se deveria escolher entre a revolução ou a educação. Um motivo que daria razão à leitura de Starobinski (1991) seria as múltiplas contradições entre as obras de Rousseau.

Por sua vez, Cassirer (1999), acusado por Starobinski de realizar uma leitura idealista do pensamento de Rousseau, afirma que apesar das "contradições" entre o Segundo Discurso e o Contrato Social, essas obras se coadunam e se complementam, pois as contradições entre as obras são tão pequenas que só se pode explicar uma a partir da outra. Para Coutinho (1996), as "contradições" no pensamento de Rousseau são na verdade "uma totalidade dialética", sobre a qual o Contrato Social é visto como uma proposta - no nível normativo do dever ser - de uma formação social e política alternativa àquela que aparece no Segundo Discurso - análise situada no âmbito do ser. Isso se dá, segundo Coutinho (1996), porque Rousseau discorda profundamente do ser da desigualdade e da opressão; e desse modo o filósofo genebrino teria proposto o dever ser de uma formação social na qual a liberdade e a igualdade se articulam de maneira indissociável, visando uma utopia alternativa.

Segundo essa leitura, Rousseau propõe no Contrato Social um modelo alternativo de sociedade, que sem renegar as conquistas fundamentais do progresso, elimina as principais causas e manifestações das degenerescências que eram apontadas no Segundo Discurso enquanto características da sociedade civil. Para além da leitura de Dalbosco (2014), como se viu anteriormente, e Cassirer (1999) e Coutinho (1996), Neuhouser (2008; 2013; 2014) afirma que o Segundo Discurso deve ser lido em consonância com o Contrato Social e com Emilio, de modo que o Segundo Discurso é visto como diagnóstico, e as obras posteriores como o prognóstico rousseauniano. Para Neuhouser (2008, p. 50, n. 43):

[...] o Segundo Discurso mostra que a natureza humana (original) não é 
a fonte do mal, miséria e servidão, enquanto o Contrato Social e Emilio demonstram que a dependência inerradicável dos seres humanos e sua consequente necessidade de viver em sociedade podem em princípio ser reconciliadas com a aspiração essencial de ser livre, feliz e não alienado. Juntos, esses três trabalhos mostram que a miséria e o mal que permeiam a história humana não são consequências inevitáveis da natureza (original) dos indivíduos humanos ou de sua necessidade de sociedade, ou da combinação dos dois [...]

\section{Considerações finais}

Starobinski (1991), como se viu, afirmava que o Contrato Social inaugurava as ideias de vontade geral e lei racional de uma vez, sem caminhos intermediários. O autor afirmava que Os Discursos e o Contrato Social de Rousseau não são um esforço destinado a transformar o mundo, mas é uma efusão do sentimento em busca do ideal rousseauniano, i.e., recusa-se os costumes corrompidos da sociedade moderna, descrevendo a bondade natural, exprimindo suas quimeras e traçando um autorretrato. Porém, contra essa leitura de Starobinski, acredita-se que a tese que afirma que as obras de Rousseau devem ser lidas em conjunto, como um todo, que apesar de não ser harmônico, é dialético, e permite justamente afirmar que Rousseau é um filósofo do seu tempo, um pensador da modernidade e da liberdade, de modo que as suas críticas à sociedade de sua época não poderiam ser vistas como uma defesa ao período pré-moderno ou da legitimação do totalitarismo (como afirmado por Costa (2017)). Com isso, não se quer afirmar que as leituras de Costa e Starobinski não são plausíveis, mas sim que a continuidade entre, especialmente, o Segundo Discurso e o Contrato Social leva o pensamento de Rousseau a um novo caminho interpretativo, sobre o qual reconhece-se a dialética da liberdade e da perfectibilidade (Coutinho, 1996), diferenciando o papel do diagnóstico (realizado na obra de 1754) do caráter normativo (presente na principal obra política de Rousseau, onde impera as normas e leis para uma organização social justa). Julga-se essa diferenciação, apesar de muitas vezes ignorada pelos leitores de Rousseau, como fundamental para uma boa leitura das obras do genebrino. 
É a partir da tese de continuidade entre as obras de Rousseau que se pode afirmar que Rousseau consegue defender as desigualdades morais e políticas como independentes das pessoas, colocando a responsabilidade sobre as instituições sociais, de modo que os vícios humanos não são decorrentes dos desejos humanos, mas dos arranjos sociais. A ideia é que o amor-próprio possui, em si mesmo - enquanto um sentimento artificial -, um caráter ambíguo e pode assumir características positivas e negativas, dependendo do modo como as organizações sociais serão moldadas. Reconhece-se, assim, que as desigualdades sociais são oriundas da disputa entre as pessoas pelas melhores posições sociais, e que elas (as desigualdades sociais) não são reflexos das desigualdades naturais entre as pessoas, assim como também não são apenas reflexos dos interesses individuais das pessoas, i.e., do egoísmo (como apontava Viroli, 2003). Entretanto, se é verdade que as desigualdades morais e políticas são reflexos do amor-próprio, também é verdadeiro que o amor-próprio não necessariamente leva as pessoas a desejarem serem vistas como melhores que as outras pessoas, isso dependerá do modo como as instituições sociais serão moldadas. Segundo Dent (1989), Cohen (2010), Dalbosco (2014) e Neuhouser (2013; 2014), isso se deve ao fato de que no pensamento de Rousseau o amorpróprio possui duas leituras antagônicas, a inflamada e a igualitarista.

Ao se assumir a tese que o amor-próprio possui duas características distintas, pode-se defender que no pensamento de Rousseau as desigualdades possuem um caráter relacional (como afirmado por Viroli (2003) e Neuhouser (2008, 2013, 2014)). E, portanto, pode-se afirmar que Rousseau é um autor fundamental (para não usar a expressão pai) do igualitarismo social. Frente ao igualitarismo de fortuna (Luck egalitarianism) ${ }^{10}$, o igualitarismo

10 Segundo Anderson (1999), autores como Dworkin, Rakowski, Roemer, Van Parijs, Arnerson, G.A. Cohen e Nagel devem ser vistos como defensores do igualitarismo de fortuna, sobre o qual haveria a divisão interna entre o igualitarismo de bem-estar (Arneson, Cohen, Roemer, provavelmente Nagel) e o igualitarismo de recursos (Dworkin, Rakowski, Roemer). Para que se possa 
social defende que há um status de igualdade moral inerente a todas as pessoas, e que, portanto, uma sociedade justa é aquela que respeita essa igualdade ${ }^{11}$. Desse modo, as considerações sobre justiça social não se dão em discussões meramente distributivas ou redistributivas, mas enquanto discussões que levam em conta os valores relacionais das pessoas (i.e., o status de igualdade moral). A busca pela igualdade, segundo o igualitarismo social, não se dá por meio (ou objetivando) da própria igualdade, mas em vista de outros valores sociais - onde a igualdade é um valor importante, mas não único.

Acredita-se, portanto, que o pensamento de Rousseau pode ser lido dentro do escopo do igualitarismo social, pois o problema da desigualdade não é visto por meio do prisma das diferenças monetárias entre as pessoas - a diferença de renda e riqueza -, assim

exemplificar a diferença entre o igualitarismo de fortuna e o igualitarismo social, utiliza-se do seguinte exemplo extraído de O'Neill (2013): uma sociedade que é hierarquicamente estruturada, sobre a qual a alocação das pessoas nos cargos de poder, prestígio e status é determinada inteiramente com base nas consequências das escolhas feitas por esses indivíduos, com uma provisão para as diferenças entre talento individual, e que, portanto, vai além dos procedimentos de uma sociedade meramente meritocrática, de modo que as posições ocupacionais (e, por hipótese, alocações de poder, prestígio e posição social) são feitas com base nas escolhas (genuínas) feitas pelas pessoas (por exemplo, no que diz respeito à decisões sobre caminhos educacionais, trade-offs de trabalho, etc.) é vista pelo igualitarismo de fortuna como sendo justa, porque não há - se supõe desigualdades não escolhidas (i.e., não há desigualdades que não sejam rastreáveis aos efeitos da escolha individual). Sobre o prisma do igualitarismo não-intrínseco, porém, essa sociedade é vista como profundamente desigual em vários dos seus aspectos, pois - de acordo com O’Neill (2013) - quando se aceita o igualitarismo pluralista de Scanlon, por exemplo, a preocupação não é erradicar as desigualdades distributivas (de renda e riqueza, por exemplo), mas eliminar as preocupações com tipos particulares de consequências experimentais (em termos do status e do respeito próprio dos indivíduos e da qualidade de suas relações sociais) geradas por diferentes conjuntos possíveis de arranjos socioeconômicos.

11 Pode-se defender que o igualitarismo social, além de estar presente no pensamento de Rousseau, também se encontra nas teses de autoras e autores como Samuel Scheffler, Thomas Scanlon, Martin O'Neill, Elizabeth Anderson, tendo seu principal expoente o filósofo estadunidense John Rawls. 
como as desigualdades sociais não são vistas como uma consequência inerente das diferenças humanas. O problema das desigualdades sociais, para Rousseau, assim como para os igualitaristas, é que elas implicam - como a própria denominação no pensamento do filósofo genebrino já deixa claro - em desrespeitos ao status moral de igualdade entre as pessoas. Outro ponto consonante entre o igualitarismo social e Rousseau é que as desigualdades morais e políticas, por dependerem das organizações sociais, não são impossíveis de serem extirpadas ou ao menos amenizadas por meio de um regime econômico e social justo (ou menos injusto possível).

Dessa forma, pode-se afirmar que no Segundo Discurso a denúncia de Rousseau não é contra uma natureza humana corrompida a partir do abandono do estado mais igualitário de todos, mas contra uma organização social corrompida e altamente desigual - e que corrompe as pessoas. O objeto da crítica de Rousseau é, portanto, a organização social injusta, que permite desigualdades exorbitantes que desrespeitam o caráter moralmente igual das pessoas. Extrapolando um pouco os limites desse trabalho, pode-se afirmar que Rousseau estava olhando para o capitalismo nascente de seu tempo, e percebendo as injustiças que seriam cometidas em nome dessa organização social. Resumindo, ao se olhar os trabalhos de Rousseau como complementares, pode-se afirmar que: (i) as desigualdades são normativas e dependem do modo como as instituições serão moldadas; (ii) é possível defender a tese da bondade humana; (iii) e se pode argumentar em favor da criação de um estado civil justo; (iv) de modo que ii e iii, que são objetos do Contrato Social, não se tornam impossíveis, apesar do diagnóstico do Segundo Discurso.

\section{Referências}

ANDERSON, Elizabeth S. What's the point of equality? Ethics, 1999, vol. 102, n. 2. pp. $287-337$.

CASSIRER, Ernest. A questão Jean-Jacques Rousseau. Trad.: Erlon José 
Paschoal, Jézio Gutierre; revisão da tradução: Isabel Maria Loureiro. São Paulo: Editora UNESP, 1999.

COHEN, Joshua. Rousseau: A Free Community of Equals. New York: Oxford University Press (OUP), 2010.

COSTA, Marta Nunes da. Os Dilemas de Rousseau. Uma leitura crítica d' $O$ Contrato Social. Disputatio: Philosophical Research Bulletin, Vol. 6, No. 7 (2017), pp. 43-80.

DALBOSCO, Claudio Almir. Condição humana e formação virtuosa da vontade: profundezas do reconhecimento em Honneth e Rousseau. In: Educação e Pesquisa. São Paulo, v. 40, n. 3, p. 799-812, jul./set. 2014. pp. 799-812.

DENT, N. J. H. Rousseau: An Introduction to his Psychological, Social and Political Theory. Oxford, New York: Basil Blackwell, 1989.

LEPAN, Géraldine. Rousseau et le patriotism. Paris: Honoré Champion, 2007.

NEUHOUSER, Frederick. Rousseau's Critique of Economic Inequality. Philosophy \& Public Affairs, 41, no. 3, 2013.

NEUHOUSER, Frederick. Rousseau's critique of inequality: reconstructing the second discourse. Cambridge: Cambridge University Press, 2014.

NEUHOUSER, Frederick. Rousseau's Theodicy of Self-Love. Evil, Rationality, and the Drive for Recognition. New York: Oxford University Press (OUP), 2008.

O’NEILL, Martin. Constructing a Contractualist Egalitarianism: Equality after Scanlon. Journal of Moral Philosophy, Vol.: 10. 2013. pp. 429-461.

PETRONI, Lucas. A Moralidade da Igualdade. 2017. 293f. Tese (Doutorado em Ciência Política) - Faculdade de Filosofia, Letras e Ciências Humanas, Universidade de São Paulo, São Paulo, 2017.

ROUSSEAU, Jean-Jacques. Discurso sobre a Economia Política. Trad.: Maria Constança Peres Pissarra. Petropolis, RJ: Vozes, 2017. (coleção Vozes de Bolso).

ROUSSEAU, Jean-Jacques. Discurso sobre a Origem e os Fundamentos da Desigualdade entre os Homens. Trad.: Paulo Neves. Porto Alegre: LP\&M, 2013. 
ROUSSEAU, Jean-Jacques. O Contrato Social. Trad.: Antônio de Pádua Danesi. $3^{\mathrm{a}}$ edição. São Paulo: Martins Fontes, 1996. (coleção Clássicos).

STAROBINSKI, Jean. Jean-Jacques Rousseau: a transparência e o obstáculo; seguido de sete ensaios sobre Rousseau. Trad.: Maria Lucia Machado. São Paulo: Companhia das Letras, 1991.

VIROLI, Maurizio. Jean-Jacques Rousseau and the 'well-ordered society'. Trad.: Derek Hanson. Cambridge: Cambridge University Press, 2002 [1988]. 